[Bull. Agr. Chem. Soc. Japan, Vol. 24, No. 7, p. 687 692, 1960]

\title{
Studies on Mannan in Wood Pulp
}

\section{Part IV. Isolation and Purification of Glucomannan}

\author{
By Tetsuo Koshrjima \\ Wood Research Institute, Kyoto University \\ Received June 6, 1960
}

\begin{abstract}
Glucomannan was isolated from holocellulose pulp of pine (Pinus densiftora Sieb. et Zucc.) using dimethylsulfoxide and aqueous alkali. It was found that there were present also, in the pulp, separate two glucomannans as the possible contaminants. Purification of the glucomannan by extraction with dimethylsulfoxide, the following acetylation and fractionation resulted essentially. homogeneous glucomannan triacetate $[\alpha]_{D}-30.7^{\circ}$ contained mannose and glucose only in the ratio $36: 10$. Measurements of intrinsic viscosity in the chloroform solution gave [ $\eta] 0.776$ and 0.291 for high and low molecular parts of the acetate respectively. The glucomannan derived its acetate showed $[\alpha]_{D}-36.5^{\circ}$ and $78.5 \%$ mannose content.
\end{abstract}

Recently it has been found that coniferous woods and their pulp contained glucomannans which have been studied by Aspinall ${ }^{1)}$, Dutton ${ }^{2}$, Hamilton ${ }^{3,8)}$, Lindberg ${ }^{4)}$, Timell ${ }^{5)}$, Wise ${ }^{(6)}$, Jones ${ }^{3,102}$ and their co-workers. In spite of their important contributions in this field, the structural feature of glucomannan remains unclear in many points. Jones? ${ }^{7)}$ reported the presence of galactose residues in the glucomannan but he also considered it as originated from galactomannan. On the other hand, Hamilton ${ }^{3)}$ thought that the galactose residue is attributed to a separate galactoglucomannan. Further, there are divergences of opinions on the ratio of mannose to glucose, the presence of cellobiose fragment as a constituent of the glucomannan

1) G. O. Aspinall, R. A. Laidlaw and R. B. Rashbrook, 1 . Chem. Soc., 1957, 4444.

2) G. G.S. Dutton and K. Hunt, J. Am. Chem. Soc, 80, 5697 (1958).

3) J. K. Hamilton and H. W. Kircher, J. Am. Chem. Sac., 8o, 4703 (1958).

4) B. Lindberg and H. Meier, Svensk Papperstidn., 60, 785 (1957).

5) T. E. Timell and A. Tyminski, TAPPI, 40, 519 (1957).

6) E. Merler and L.E. Wise, TAPPI, 41, 80 (1958).

7) J. K. N. Jones and T. J. Painter, J. Chem. Soc., 1959, 573.

8) J. K. Hamilton and E. V. Partlow, J. Am. Cbem. Sar., 80 , 4880 (1958).

9) T. Koshijima and I. Tachi, This Bulletin, 22, 11 (1958).

10) J. K. N. Jones and T. J. Painter, J. Chem. Soc., 1957, 669 or the configuration and size of the molecule. It may be considered that these questions are all owing to the difficulties of removing the contaminants from glucomannan molecule. In the previous paper ${ }^{9}$, the presence of glucomannan in dissolving pulp prepared from pine was recognized by isolation of octaacetyl 4-O- $\beta$-Dglucopyranosyl $-\alpha-D$-mannose from the acetolysis product. This paper is concerned with separation of the glucomannan from the contaminants and characterization of the pure specimen. This also includes the detection of the contaminating hexosans. Polysaccharides constructing hemicellulose were isolated by successive extractions with dimethylsulfoxide and aqueous alkali from holocellulose pulp of pine which was free from pectin and water-soluble polysaccharides. First extraction was effected with dimethylsulfoxideacetic acid mixture which gave a polysaccharide mixture (I), $[\alpha]_{\mathrm{D}}-39^{\circ}$, composed of 4-O-methylglucurono-araboxylan ${ }^{113}$ and a new type of glucomannan (II). Dimethylsulfoxide-boric acid was then used as extractant and the extracted material was purified by adsorption to Amberite

11) J. K. Familton, E. V. Partow and N. S. Thompson, TAPPI, 41, 803 (1958); ibid., 41, 811 (1958). 
IR-A 400. The material eluted from the resin with $1 \mathrm{~N}$ ammonium carbonate solution was a new type of glucomannan (II), $[\alpha]_{D}^{23}-8^{\circ}$ (water) contained 3.8 parts of mannose and one part of glucose. The constitution of the glucomannan is under experiments. A large part of 4-O. methylglucurono-araboxylan (III), $[\alpha]_{\mathrm{D}}-42^{\circ}$ was obtained from the residual pulp by the extraction with 1\% sodium hydroxide and the usual glucomannan eluted for the first time by the following 10\% sodium hydroxide extractions. It was purified using dimethylsulfoxide which dissolved only 4-O-methylglucurono-araboxylan (B), $\left[\alpha^{\prime}\right]_{D}-49^{\circ}$ and left glucomannan (IV), $[\alpha]_{D}$ $-39^{\circ}$. Mannose and glucose were present, respectively, in a ratio $3.6: 1$ with trace of xylose and galactose in (IV). The glucomannan (IV) precipitated with methanol from its water solution was made free from water by washing with methanol and the methanol-wet material was acetylated twice with excess of acetic anhydride and pyridine. The fully acetylated (IV) was then fractionally precipitated from the chloroform solution with petroleum ether and the pure glucomannan triacetate fractions were combined, $[\alpha]_{\mathrm{D}}-30.7^{\circ}$ (chloroform) (see Table I). Deacetylation of the acetate with sodium methoxide resulted glucomannan $[\alpha]_{D}-36.5^{\circ}(10 \%$ $\mathrm{NaOH}$ ) contained 78.5\% mannose residue. Paper chromatography showed the presence of mannose and glucose only. The intrinsic viscosity of a solution of fraction (22) and (31) in chloroform was 0.776 and $0.291100 \mathrm{ml} / \mathrm{g}$ respectively. These correspond to average D.P. of 146 and 55 when Staudinger and Daumiller's constant for cellulose triacetate, $\mathrm{Km} \cdot 10^{4}=5.3$ is applied to the glucomannan triacetate. A part of the acetylated glucomannan was fractionated by Jones and Painter's procedure ${ }^{72}$ and divided into fraction $(\mathrm{GM})$ and $(\mathrm{X})$, the latter being fractionally precipitated in the same way as above described (Table II). Fraction (GM) was the glucomannan triacetate $[\alpha]_{\mathrm{D}}-30.6^{\circ}$ containing a small amount of galactose which, however, had also a tendency to distribute over fraction $(\mathrm{X})$. This result indicates that galactose residues may be origi- nated from the other polysaccharides.

A part of the extract contained (IV) precipitated upon neutralizatson with acetic acid. The precipitate purified with alkali was a separate glucomannan $(V)$ indicating a specific optical rotation of $[\alpha]_{D}-32^{\circ}$ and consisted of four parts of glucose and one part of mannose. The results of the fractionation (Table I) indicates that the glucomannan acetate prepared is composed of two or three polysaccharides. It is probable that the acetate of this type of glucomannan $[\alpha]_{\mathrm{D}}-19^{\circ}{ }^{12}$ contaminates the higher molecular part of the present glucomannan acetate.

\section{EXPERIMENTAL}

\section{Paper Chromatography}

Aniline hydrogen phthalate was used as spray reagent throughout the experiment. For the separation of neutral sugars solvent (a), ethylacetate-pyridine-water 10:4:3, and for uronic acid fragments solvent (b), ethylacetateacetic acid-formic acid-water 18:3:1:4 were used. respectively. Measurement of the sugar-ratio in the fractionated glucomannan acetate was made on the revealed spots which were cut off from the paper, and weighed after conditioning in desiccator for twenty-four hours. In each of the cases, five series of the chromatogram of the hydrolyzate were developed two times with solvent (a) under the same conditions and the ratios of spot-weights of mannose to glucose were calculated from. five specimens. From the average value of the ratios. expressed in logarithm, the ratio of the amount of mannose to glucose in the hydrolyzate of the deacetylated glucomannan was determined immediately using the calibration curve $I$ in Fig. 1 which showed that the ratios of spot-weights were proportioned to the ratios of sugar-amounts adsorbed to the paper in a fairly range when both of the ratios were calculated on the corresponding values of glucose and expressed with logarithms. In this way, the ratios of xylose to glucose and galactose to glucose were determined by the curve II and III, respectively.

\section{Preparation of Holocellulose Pulp}

Delignification of acetone-extracted wood meal $(360 \mathrm{~g}$ ) was effected by four times chloriting ${ }^{13}$ followed by one treatment with chlorine and monoethanolamine ${ }^{14)}$. The holocellulese $(240 \mathrm{~g})$ contained $4.26 \%$ Klason-lignin was

\footnotetext{
12) T. Koshijima, J. Japan Wrood Res. Soc., in press.

13) T. Koshijima, ibid in press.

14) T. E. Timell and E. C. Jahn, Svensk Papperstidn, 54, 831
} (1951). 


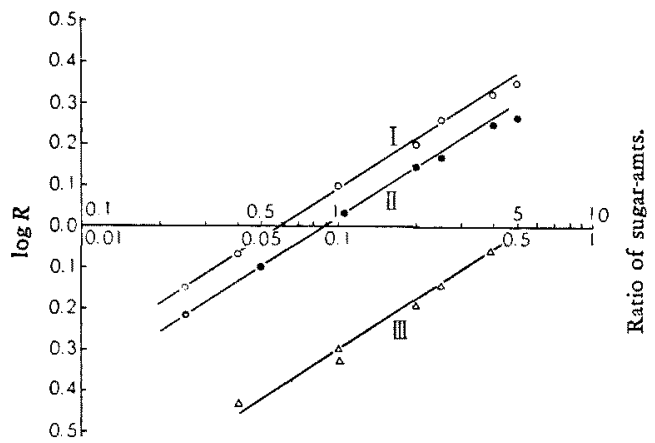

FIG. 1.

For xylose and galactose, abscissa is graduated in one-tenth of the scale designed for mannose.

$$
\begin{aligned}
& \text { I. Mannose : glucose. } \\
& \text { II. Xylose : glucose } \\
& \text { III. Galactose : glucose } \\
& \text { R: Ratio of spot-wt. }
\end{aligned}
$$

extracted with $0.5 \%$ ammonium oxalate $(\mathrm{pH}, 6.3)$ for twenty hours and the water suspension was then beaten in a laboratory beater. This treatment resulted very swollened holocellulose pulp which was soaked in water (10 1) over-night and filtered, water-soluble polysaccharide (A) $(3.5 \mathrm{~g})$ being obtained from the filtrate as usual manner. Fraction (A) showed $[\alpha]_{D}^{20}-37^{\circ}(10 \% \mathrm{NaOH}$, $c, 1.0)$ and contained mannose $(26.4 \%)$, glucose, xylose, arabinose, galactose and 4-O-methylglucuronic acid. The chloriting of the residual lignin in the pulp was repeated more three times using the same reagent and one-half of the reaction time. The resultant pulp (197 g) was washed with water, methanol, benzene and air-dried: Klason-lignin, 1.88; mannose residue, 13.8; Ac, 1.46\%. Isolation of Polysaccharides Constructing Hemicellulose

Air-dried pulp (157g) was extracted with dimethylsulfoxide-acetic acid and then dimethylsulfoxide-boric acid as described in the previous report ${ }^{13)}$. Dimethylsulfoxide-acetic acid extraction yielded a polysaccharide mixture (I) $(2.16 \mathrm{~g}) ;[\alpha]_{\mathrm{D}}^{20},-39^{\circ}(1 \% \mathrm{NaOH}, \mathrm{c}, 1.0)$; Ac, 2.41 ; mannose residues, 22.4\%. Paper chromatography (solvent $\mathrm{a}$ and $\mathrm{b}$ ) showed the presence of xylose, arabinose, mannose, glucose, galactose and 4-O-methylglucuronic acid in the hydrolyzate. Dimethylsulfoxideboric acid extract was composed of a glucomannan $(1.28 \mathrm{~g})$ as main product which contained $4.43 \%$ Ac. and mannose, glucose, galactose and xylose as component sugars (solvent a). It was treated with Amberite IR-120 and IR A-400 (carbonate form) resin with stirring. The anion-exchanger was washed with water until negative for anthrone and then soaked in $1 \mathrm{~N}$ ammonium carbonate solution for one month. The resin was separated from the solution which was evaporated to a small volume in vacuo and precipitated with 10 volumes of ethanol. The resultant white powder (II) was easily soluble in water and was composed of mannose and glucose in a ratio $3.8: 1$ with trace amounts of xylose, yield $1.21 \mathrm{~g}$, $[\alpha]_{\mathrm{D}}^{22}-8^{\circ}$ (water, c, 1.0), $-4^{\circ}(106 \mathrm{NaOH}, \mathrm{c}, 1.0)$. Uronic acid fragments in the hydrolyzate showed the presence of methyl-glucuronic acid and an unknown spot neighboring start line (solvent $b$ ).

Dimethylsulfoxide-extracted pulp $(240 \mathrm{~g})$ was mixed with $1 \%$ sodium hydroxide solution (31) and allowed to stand for thirty minutes. The filtrate and washings acidified with acetic acid were combined and the precipitate produced after three days was separated. The clear, light yellow extracts were made precipitate by addition of 3 volumes of methanol, removed by centrifugation, resuspended in methanol and dried, yield $14 \mathrm{~g}$. The bulky white powder (III) showed an optical rotation of $[\alpha]_{\mathrm{D}}^{15}-42^{\circ}(10 \% \mathrm{NaOH}, c, 0.9)$ and the paper chromatography followed by hydrolysis of (III) indicated the presence of a large amount of xylose, arabinose and 4-O-methylglucuronic acid fragments (solvent $a$ and b).

Ten percent sodium hydroxide solution (2.5 I) was added to the residual pulp without drying and nitrogen gas bubbled through the suspension for one bour. Extraction was continued for twenty-four hours and then the extract was filtered and washed with this solution through cloth into the vessel containing acetic acid with external cooling. The acidic extract was turbid and, after five days, the precipitate ( $\mathrm{Va}$ ) produced removed by centrifugation. The residual pulp was extracted again with $10 \%$ sodium hydroxide and the centrifugated liquor of two extracts were combined and dialyzed through gel cellophane for two weeks. The water solution was evaporated to one-fifth and precipitated with methanol, the precipitate being removed by filtration, resuspended in methanol, filtered and washed with methanol, yield $34 \mathrm{~g}$ (IVa). Paper chromatography of the hydrolyzate showed the presence of a large amount of mannose, glucose, galactose and xylose (solvent a).

The precipitate (Va) was washed with water by centrifugation, resuspended in methanol-water $(1: 3)$ and the supernatant liquor discarded. This treatment was repeated six times and the final precipitate recovered from a methanol suspension. The methanol-wet precipitate was dissolved in 1\% sodium hydroxide, neutralized with acetic acid and the resultant precipitate was centrifuged. It was dissolved again in 10\% sodium hydroxide and made precipitate as above. This was repeated once 
more and the final precipitate was washed with water, $50 \%$ methanol and methanol. The product (V) $(1.3 \mathrm{~g})$ contained $19.8 \% \%$ mannose residue, indicated $[\alpha]_{\mathrm{D}}^{18}-32^{\circ}$ (10\% $\mathrm{NaOH}, \mathrm{c}, 0.3)$. On hydrolysis and paper chromatography, the only sugars present were glucose and mannose (solvent a).

\section{Purification of the Glucomannan}

Polysaccharide (IVa) was suspended in dimethylsulfoxide $(800 \mathrm{ml})$ which was stirred vigorously for three hours and allowed to stand overnight. The insoluble part was removed by centrifugation and treated again with dimethylsulfoxide as described above. The light brown insoluble part was centrifuged, washed with this reagent, resuspended in methanol, filtered through cloth, washed with methanol and dried, yield $24 \mathrm{~g}$ (IV). The glucomannan (IV) indicated a specific optical rotation of $[\alpha]_{\mathrm{D}}^{18}-39^{\circ}(10 \% \mathrm{NaOH}, \mathrm{c}, 0.9)$ and contained mannose and glucose in the ratio $3.6: 1$, together with a trace amount of xylose and galactose. Dimethylsulfoxidesoluble part (B) produced a bulky precipitate by pouring into methanol. This was separated as usual manner and the resultant white powder $(9.8 \mathrm{~g})$ containing xylose, arabinose and 4-O-methylglucuronic acid as component sugars, showed $[\alpha]_{\mathrm{D}}^{15}-49^{\circ}(1 \% \mathrm{NaOH}, c, 1.0)$.

\section{Acetylation of the Glucomannan}

The glucomannan (IV) $(9.0 \mathrm{~g})$ was dissolved in warm water $\left(21,70^{\circ} \mathrm{G}\right)$ with stirring and standing for 2 days at $0^{\circ}$, the insoluble material being separated by centrifugation. The centrifugate was concentrated in vacuo and poured into 5 volumes of methanol. The white precipitate separated was resuspended in methanol, filtered through cloth, and methanol was removed as much as possible by evaporation under reduced pressure. The methanol-wet glucomannan was dispersed in dry pyridine $(100 \mathrm{ml})$ and then there was added dropwise $130 \mathrm{ml}$ of acetic anhydride with vigorous stirring and ice-cooling. The temperature of the reaction mixture was maintained to $30^{\circ}$ during this time, after which stirring was continued at room temperature for twentyfour hours. Portions of pyridine and acetic anhydride were added over five days until a total of $210 \mathrm{ml}$ of pyridine and $290 \mathrm{ml}$ of acetic anhydride had been added. After addition of these reagent, the temperature of the liquid was raised to $40^{\circ}$ which was maintained for twenty-four hours with continuous stirring. The resultant light brown solution was poured into ice-water (31), whereupon the acetylated glucomannan appeared as a flocculent precipitate. The suspension was thoroughly extracted with chloroform but a large portion of the glucomannan acetate formed emulsion, which was ex- tracted with chloroform several times, the clear chloroform extracts being combined and used for the preparation of fraction (GM I) and (X I). Partly acetylated glucomannan (Ac, 30.5\%, $11 \mathrm{~g}$ ) was recovered from the emulsion and acetylated again using $130 \mathrm{ml}$ of dry pyridine and $113 \mathrm{ml}$ of acetic anhydride. The reaction was complete for three hours at $40^{\circ}$ and then the resultant brown solution poured into ice-water containing hydrochloric acid $(30 \mathrm{~g})$. The fibrous precipitate produced was filtered, washed with water and dried over anhydrous calcium chloride and then sodium hydroxide, yield $11.5 \mathrm{~g}, \mathrm{Ac}, 43.9 \%$.

Fractional Precipitation of the Glucomannan Acetate

The acetate $(4.0 \mathrm{~g})$ was dissolved in chloroform $(300$ $\mathrm{ml}$ ) and precipitated in the usual way by the gradual addition of equal volume of petroleum ether (b.p. 30 $50^{\circ}$ ). The precipitate was dissolved in chloroform and precipitated again as a white powder by pouring this solution into 10 volumes of petroleum ether. It was recovered and divided into three portions by fractional precipitation of its chloroform solution, each portions being refractionated further into two or three. The individual fractions were treated as described above, and the resultant white powders washed with petroleum ether and dried in vacuo. A soluble part in chloroformpetroleum ether $(1: 1)$ was made precipitate by concentration and addition of petroleum ether and the last fraction obtained. The specific optical rotation and sugar composition of each fraction indicate that fraction (22) to (32) inclusive are essentially homogeneous as given in Table I. They were combined and characterized, $[\alpha]_{\mathrm{D}}^{20}-30.7^{\circ}$ (chloroform, c, 1.0). Anal. Found : $\mathrm{COCH}_{3}$, 44.5. Calcd. for $\mathrm{C}_{12} \mathrm{H}_{16} \mathrm{O}_{8}: \mathrm{COCH}_{3}, 44.8 \%$.

\section{Deacetylation of the Glucomannan Triacetate}

To a solution of the glucomannan triacetate $(180 \mathrm{mg})$ in chloroform $(18 \mathrm{ml}), 0.2 \mathrm{~N}$ sodium methoxide in abs. methanol $(9 \mathrm{ml})$ was added with shaking and the mixture was allowed to stand over-night at room temperature. After addition of methanol $(27 \mathrm{ml})$, acetic acid and water, the resultant white precipitate was removed by filtration and washed with 75\% ethanol, ethanol and dried, yicld $90 \mathrm{mg},[\alpha]_{\mathrm{D}}^{22}-36.5^{\circ}(10 \% \mathrm{NaOH}, \mathrm{c}, 1.3)$. Determinztion of mamnose content in the glucomannan was carried out as described in the previous report ${ }^{15)}$ which was modified the Hägglund's method ${ }^{163}$. To make complete the precipitation of mannose phenylhydrazone, however, the hydrolyzed solution was kept to fourty-eight hours

15) T. Koshijima and I. Tachi, This Bulletion, 21, 253 (1957). 16) E. Hagglund and L.C. Bratt, Sevente Kem. Tidskr, 48, $125(1936)$. 
Table I. Fractional Precipitation of the Glucomannan acetate

\begin{tabular}{|c|c|c|c|c|c|c|c|}
\hline Fraction & Acetyl, $\%$ & Yield, $\%$ & $\begin{array}{c}{[\alpha] \mathrm{D}} \\
\text { in Chloroform }\end{array}$ & Xylose & Mannose & Glucose & Galactose \\
\hline 1 & 43.2 & 46.3 & - & 0.11 & 2.5 & 1 & 0.15 \\
\hline 11 & & 22.1 & - & 0.07 & 1.4 & 1 & 0.12 \\
\hline 12 & & 11.8 & -21.8 & 0.03 & 1.0 & 1 & 0.13 \\
\hline 13 & & 3.8 & -19.4 & Trace & 1.4 & 1 & Trace \\
\hline 2 & 44.8 & 27.5 & -30.0 & Trace & 3.6 & 1 & None \\
\hline 21 & & 1.8 & -44.5 & Trace & 4.6 & 1 & None \\
\hline 22 & & 14.0 & -30.6 & None & 3.7 & 1 & None \\
\hline 23 & & 6.8 & -30.8 & None & 3.5 & 1 & None \\
\hline 3 & 44.3 & 25.8 & -30.2 & None & 3.6 & 1 & None \\
\hline 31 & & 18.2 & -30.7 & None & 3.6 & 1 & None \\
\hline 32 & & 3.2 & -30.6 & None & 3.7 & 1 & None \\
\hline 4 & & 0.5 & -20.5 & None & 2.1 & 1 & None \\
\hline
\end{tabular}

a) Expressed on the original acetate.

Table II. Fractionation of the Glucomannan ACetate by Jones' Procedure

$\begin{array}{cccccccc}\text { Fraction } & \text { Acetyl, \% } & \text { Yield, } \% \text { in Chloroform } & \text { Xylose } & \text { Mannose } & \text { Glucose } & \text { Galactose } \\ \text { GMI } & 44.2 & 0.5 & -30.8 & \text { Trace } & 3.5 & 1 & 0.03 \\ \text { GMII } & 44.5 & 31.3 & -30.6 & \text { None } & 3.6 & \text { I } & 0.03 \\ \text { XI } & & 0.8 & -41.0 & 0.23 & 2.7 & 1 & 0.20 \\ \text { XII } & & 28.0 & - & - & - & - & - \\ \text { EI } & & 5.0 & -33.7 & 0.20 & 2.1 & 1 & 0.05 \\ 2 & & 11.0 & -31.1 & 0.03 & 3.6 & 1 & \text { None } \\ 3 & & 3.0 & -28.6 & \text { Trace } & 3.4 & 1 & \text { None } \\ 4 & & \text { Trace } & - & \text { Trace } & 2.0 & 1 & \text { None } \\ \text { R } & & 9.1 & - & 0.20 & 1.4 & 1 & 0.06\end{array}$

a) Expressed on the original acetate.

at $0^{\circ}$ and washings of the precipitate were effected successively by two of $1 \mathrm{ml}$ of cold water, two of $1 \mathrm{ml}$ of cold ethanol and $2 \mathrm{ml}$ of ether for $224 \mathrm{mg}$ of the hydrazone. The hydrazone derived from the glucomannan $(67.0 \mathrm{mg})$ was $82.0 \mathrm{mg}$ : this corresponds to $78.5 \%$ mannose residue.

Fractionation of Glucomannan Acetate by the Jones' Procedure

To the chloroform solution of the glucomannan acetate $(3.5 \mathrm{~g}$ in $500 \mathrm{ml})$, saturated sodium bicarbonate solution was added and shaken. The chloroform layer which separated was removed and again treated with this reagent further two times. It was combined to the washings of emulsion, washed with water, dried over anhydrous sodium sulfate, concentrated to $150 \mathrm{ml}$ and poured into petroleum ether. The glucomannan triacetate (GM II) was recovered as white yellow powder, yield $0.94 \mathrm{~g}[\alpha]_{\mathrm{D}}^{18}-30.6^{\circ}$ (chloroform, c, 1.5).

The emulsion was washed with chloroform, acidified with ice-cold $1 \mathrm{~N}$ hydrochloric acid and shaken with chloroform, whereupon chloroform layer did not separate from the emulsion. Equal volume of water was added and chloroform layer separated. The dried chloroform solution (X II) was fractionally precipitated as before and fraction (El) to (E4) obtained. The emulsion remaining after the repeated extraction with chloroform was recovered by pouring into methanol (ER). The partly acetylated glucomannan was treated in the same way as described here and small amount of glucomannan triacetate (GM 1 ) was obtained, $[\alpha]_{\mathrm{D}}^{18}-30.8^{\circ}$ (chloroform, c, 1.0), as well as fraction (X I) (see Table II).

\section{Determination of Intrinsic Viscosity}

The intrinsic viscosity was measured on the chloroform solution of fraction (22) and (31) at $20 \pm 0.01^{\circ}$ using an Ubbelohde capillary viscometer. In each of the cases, the reduced viscosity was determined at 3 different concentrations and linearly extrapolated to zero concentration. Fraction $(22), \eta_{s p} / c ., 1.141,1.048,0.961 ;[\eta], 0.776$. 
Fraction $(31), \eta_{s p} / \mathrm{c} ., 0.538,0.478,0.420 ;[\eta], 0.291$.

Acknowledgement The author wishes to express his sincere gratitude to Prof. Dr. I. Tachi, Kyoto University, for his helpful guidance and encour- agement and Prof. K. Kitao, Wood Research Institute, Kyoto University, for his valuable advices. Thanks are also due to Dr. A. Nakai, Kyoto University, for measurement of viscosity.

[Bull. Agr. Chem. Soc. Japan, Vol. 24, No. 7, p. 692 695, 1960]

\author{
Studies on the Conjugated Lipids \\ Part XIV*. Fatty Acid Constituents of Sphingomyelin \\ from Horse Spinal Cord** \\ By Yasuhiko FujıNo and Takashi Negrshi \\ Department of Dairy Science, Obihiro Zootechnical College, Obihiro, Hokkaido, Japan \\ Received June 9, 1960
}

\begin{abstract}
The chemical nature of fatty acids was studied on sphingomyelin which was prepared from horse spinal cord. Nervonic, palmitic, stearic and behenic acids were isolated from the hydrolysate of the sphingomyelin preparation. The presence of behenic acid in sphingomyelin has in this paper been reported for the first time.
\end{abstract}

It is known that several kinds of fatty acid can attach to the amino group of the shingosine moiety of shingomyelin, the structure of which is shown in Fig. 1. However, an assortment of fatty

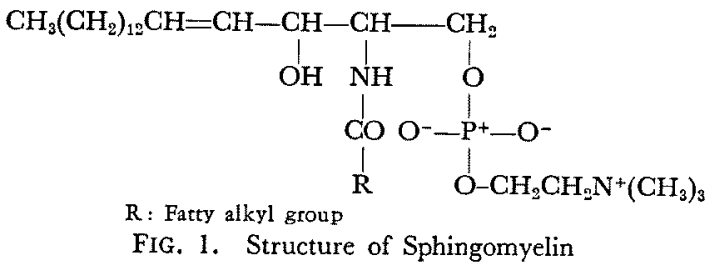

acids in shingomyelin from a certain animal tissue seems to be almost settled, althouh some confusion and inconsistencies on this point are seen in the literature. This may be unavoidable

\footnotetext{
* Part XIII: This Bulletin, 22, 426 (1956).

** A preliminary communicarion of this work has been published in the Nature, 184, 817 (1959).
}

because sphingomyelin prepared by the older methods might often have been contaminated with other lipids. Nowadays, it is generally believed that sphingomyelin from brain contains lignoceric, stearic and nervonic acids as the component fatty acids $^{1-3}$, and that sphingomyelin from lung or spleen contains lignoceric and palmitic acids ${ }^{3,4}$. The present authors undertook to elucidate the fatty acid constituents of sphingomyelin from spinal cord, since the tissue has never been studied in respect to this problem.

A pure sample of sphingomyelin was prepared from horse spinal cord, and hydrolyzed with methanolic sulfuric acid to produce methyl

1) P. A. Levene, J. Biol. Chem., 24, 69 (1916).

2) W. Merz, Z. Pbysiol. Chem., 193, 59 (1930).

3) S.J. Thannhauser and N. F. Boncoddo, J. Biol. Cbem., 172. 141 (1948).

4) S. J. Thannhauser, J. Benotti and N. F. Boncoddo, J. Biol. Chem., 166, 677 (1946). 